\title{
Factors Influencing the Decision on Surgery or Observation for Patients with Bethesda Category 3 (AUS/FLUS)
}

\author{
Bekir Kuru, MD, FACS \\ Department of General Surgery, Ondokuz Mayis University School of Medicine, Samsun, Turkey
}

\section{TO THE EDITORS:}

The Bethesda System for Reporting Thyroid Cytopathology (BSRTC) proposes a repeated fine-needle aspiration (FNA) for nodules with atypia of undetermined significance or a follicular lesion of undetermined significance (AUS/FLUS) on the initial FNA. ${ }^{1}$ Cibas and $\mathrm{Ali}^{1}$ reported that to increase the diagnostic accuracy of the AUS/FLUS FNA category and to prevent unnecessary surgery, two approaches have been proposed. The recommended management is clinical correlation and a repeated FNA at an appropriate interval. ${ }^{1-3}$ In some cases, the physician may choose not to repeat the FNA but to observe the nodule clinically or, alternatively, to refer the patient for surgery because of concerning clinical and/or sonographic features. ${ }^{1}$ Thus, determination of sonographic features associated for surgery or observation is important.

In their published article in the Annals of Surgical Oncology, Nagarkatti et al. ${ }^{4}$ reported that younger and male patients with Bethesda criteria for AUS/FLUS were more likely to go directly to surgery. They reported that ultrasound features such as micro-calcifications, irregular margins, and marked hypoechogenicity did not appear to influence the decision to observe the patients or refer them for surgery. The choice of surgery versus observation was primarily based on the patient's gender, the clinical judgment of the endocrinologist and/or surgeon, and the patient's preference. ${ }^{4}$ However, Nagarkatti et al. ${ }^{4}$ did not report the predictor factors for malignancy, which are important in differentiation for surgery or observation.

\section{(C) Society of Surgical Oncology 2017}

First Received: 17 October 2017;

Published Online: 30 October 2017

B. Kuru, MD, FACS

e-mail: bekirkuru@gmail.com; bekirkuru@yahoo.com
In our series, among all the thyroid FNAs performed during the study period between 2011 and 2015 at our institution, $11.3 \%$ (370 of 3270) resulted in AUS/FLUS. Of the 370 patients classified as AUS/FLUS on the initial FNA, 137 underwent surgery and 233 did not undergo surgery. The percentage of patients who were young $(<45$ years) and had a nodule size of $2 \mathrm{~cm}$ or larger was significantly higher among those who underwent surgery than among those who did not.

Among the 137 patients who underwent surgery, the predictor factors for malignancy were microcalcifications, nodule smaller than $2 \mathrm{~cm}$, solid structure, hypoechogenicity, irregular margin, and increased vascularity of the nodules. We found that sonographic features did not influence the choice for surgery. The causes for selection of older patients for observation could be comorbidity, patient preference, physician life expectancy or other reasons. However, nodule size smaller than $2 \mathrm{~cm}$ should not be a criterion for observation of patients with AUS//FLUS FNA. We support the findings of Nagarkatti et al. ${ }^{4}$ who reported that sonographic features of nodules did not influence the choice for surgery or observation, but that age significantly influenced the choice. We suggest that worrisome sonographic predictors of malignancy in patients with AUS/ FLUS FNA should be considered for surgery.

\section{REFERENCES}

1. Cibas ES, Ali SZ. The bethesda system for reporting thyroid cytopathology. Am J Clin Pathol. 2009;132:658-65.

2. Yassa L, Cibas ES, Benson CB, et al. Long-term assessment of a multidisciplinary approach to thyroid nodule diagnostic evaluation. Cancer. 2007;111:508-16.

3. Layfield L, Cochand-Priollet B, LiVolsi V, et al. Post-thyroid FNA testing and treatment options: a synopsis of the National Cancer Institute Thyroid Fine-Needle Aspiration State of the Science Conference. Diagn Cytopathol. 2008;36:442-8.

4. Nagarkatti SS, Faquin WC, Lubitz CC, Garcia DM, Barbesino G, Ross DS, et al. Management of thyroid nodules with atypical cytology on fine-needle aspiration biopsy. Ann Surg Oncol. 2013;20:60-5. 